\title{
Can the critical period be saved? A bilingual perspective*
}

\author{
ELLEN BIALYSTOK \\ Department of Psychology, York University \\ JUDITH F. KROLL \\ Department of Psychology, University of California Riverside
}

(Received: January 22, 2018; final revision received: January 23, 2018; accepted: January 23, 2018; first published online 20 February 2018)

The idea that there is a critical period (CP) for language acquisition that starts sometime after birth and ends sometime around puberty has been central to language studies since Chomsky's paradigm shift that embedded language acquisition into human biological development (for discussion, see Bialystok \& Kroll, in press). From early on, the critical period argument was loosely extended to include second language (L2) acquisition, an idea buttressed largely by anecdote: "children learn foreign languages so much better than adults" in spite of evidence to the contrary (Goldberg, Paradis \& Crago, 2008; Snow, 1987). The review by Mayberry and Kluender (2017) describes the existing literature on L2 acquisition and adds recent empirical evidence from investigations of individuals learning American Sign Language (ASL) at different ages, often as a first language (L1) to offer important clarifications and insights to this debate. Their argument rests on a clear distinction between processes used in L1 or L2 acquisition to re-evaluation of some of the more extreme claims of the $\mathrm{CP}$ view. In brief, they argue that $\mathrm{L} 2$ acquisition is not a good test of the $\mathrm{CP}$ argument, a point with which we agree. However, our view is that $\mathrm{CP}$ effects on language acquisition are even more limited than Mayberry and Kluender suggest and we offer two further arguments to support their own formidable evidence and conclusion.

The first comment addresses the shape of the curve that relates age of language acquisition to some outcome measure. Since first language acquisition typically begins at birth, the relation is irrelevant for arguments regarding the possibility of a $\mathrm{CP}$ in $\mathrm{L} 1$ acquisition, but this curve is a staple in the literature arguing for a $\mathrm{CP}$ in $\mathrm{L} 2$ acquisition. The evidence from both very large-scale studies involving millions of data points (Hakuta, Bialystok \& Wiley, 2003) and others with small numbers of participants (Johnson \& Newport, 1989) is that there is a significant negative linear correlation between these variables across the lifespan. The arguments about this linear relation revolve

\footnotetext{
* Preparation of this manuscript was supported by in part by NIH Grants HD052523 and AG048431 and NSERC Grant A2559 to EB and NSF Grants BCS-1535124 and OISE- 1545900 and NIH Grant HD082796 to JFK.
}

around the strength of the correlation and whether or not there are discontinuities in its linearity (DeKeyser, Alfi-Shabtay \& Ravid, 2010), but not that the relation is fundamentally linear. Mayberry and Kluender add to this trend by reporting evidence that the same linear function between age of acquisition and outcome has been found for individuals who learned ASL as an L1 at different ages.

How does evidence for a linear relation between age and outcome support a CP interpretation of learning? In development, a $\mathrm{CP}$ is a maturational stage in which the individual is most sensitive to the stimuli necessary for a particular kind of learning. In some cases, the CP can last for several years, such as specific aspects of visual acuity (Lewis \& Maurer, 2005). But what would it mean for a $\mathrm{CP}$ to be functional from birth until puberty or, as some evidence suggests, throughout the lifespan? Moreover, although there may be variations in the degree to which the $\mathrm{CP}$ drives learning during the window, there should not be a strong linear correlation between age and outcome WITHIN the $\mathrm{CP}$ because by definition, the entire period is a time of privileged learning. In this sense, a correlation between age and outcome is logically contrary to the conclusion of a CP. It is clear that there are profound effects of age of acquisition on learning, but age-related differences do not on their own support the presence of a CP. Such a conclusion at a minimum requires evidence that the learning cannot be carried out successfully once the CP has closed, and Mayberry and Kluender present compelling counterexamples to that notion, even for very late learners.

The second comment concerns variation in L1 and the role of L2. It has always been widely accepted that there are variable outcomes for L2 learning (for recent reviews see Baum \& Titone, 2014; Fricke, Zirnstein, Navarro-Torres \& Kroll, under review; Pierce, Genesee, Delcenserie \& Morgan, 2017). A second language may be acquired by choice or imposed by the circumstances of life. It may be acquired early in childhood or late in adulthood and learning may occur in a context that is rich in support with many other speakers of the same L2 or weak with respect to the status of the L2. Each difference in what the learner brings to new learning and what the

Address for correspondence:

Ellen Bialystok, Department of Psychology, York University, 4700 Keele Street, Toronto, Ontario M3J 1P3, Canada

ellenb@yorku.ca 
environment supports will shape the observed outcomes for both language use and its cognitive consequences. The studies that Mayberry and Kluender review suggest that the acquisition and use of sign language may be no different than spoken languages in this respect. What is critical is whether there is already an L1.

Recent discussion of language development across the lifespan reveals that there is also variation in L1 (Pakulak \& Neville, 2010), even among individuals who were exposed to their native language environment from birth and who, by CP standards, have fully acquired the L1. A range of individual differences appears to determine how the brain processes the native language grammar even for adults exposed from birth (e.g., Kasparian and Steinhauer, 2017; Tanner \& Van Hell, 2014). Far from demonstrating a stable native language system, these differences suggest a set of dynamics that not only characterize L2, but that also influence the native language. Age of acquisition alone is insufficient to capture this variation. Individuals may be functionally fluent in their L1 but rely on mechanisms that differ and that also change over time within individuals.

An important source of variation in L1 for bilinguals can be attributed to the experience of learning and using the L2. Contrary to the trajectory of skilled language development suggested by the $\mathrm{CP}$ account, recent behavioral and neural evidence on bilingualism demonstrates that the native language changes in response to learning and using the L2. Critically, those changes occur early in learning (e.g., Bice \& Kroll, 2015) and can be observed in highly proficient bilingual speakers. The plasticity of the language system reflects a dynamic that appears to be in place across the lifespan, with changes in the L1 as a function of the form of the L2 (Dussias \& Sagarra, 2007) and the nature of the environment, such as whether individuals are immersed in the L1 or L2 (e.g., Linck, Kroll, \& Sunderman, 2009). As Mayberry and Kluender point out, sign language develops and functions similarly to spoken languages, and the evidence on bimodal bilinguals, both hearing and deaf, supports that claim in the realm of crosslanguage interactions (Morford, Wilkinson, Villwock, Piñar \& Kroll, 2011; Pyers \& Emmorey, 2008). For both unimodal and bimodal bilinguals there is evidence that the two languages come to influence one another in a way that changes native language processing. Under some circumstances, particularly when a weaker L2 must be available for production, there may be the requirement to suppress the L1 to use the L2 (Misra, Guo, Bobb \& Kroll, 2012). Under other circumstances where there is frequent contact between the two languages, there may be convergence across the two languages (Ameel, Storms, Malt \& Sloman, 2005). In addition, for highly proficient bilinguals who code switch between the two languages, the processing of the grammar in both languages may change (e.g., Beatty-Martínez \& Dussias, 2017).
Mayberry and Kluender argue that the only real critical period may be for L1 acquisition. There is no doubt that the development of the neural networks responsible for language are affected by the absence of language input early in life and understanding how the brain responds to this deprivation is of interest and importance. But whether it constitutes a critical period is an issue that will depend on how liberally we understand the idea of a critical period. This keynote article makes an important point in showing how deafness and exposure to sign language may be a unique lens through which one can examine the ability of the brain to develop in response to language following a period of deprivation. We need to ask, however, what that state of deprivation tells us about the ordinary course of L1 development. The evidence we have reviewed briefly, on how the L2 comes to affect the L1, suggests that even typical L1 development does not result in a stable native language system; L2 exposure interacts with the L1 in a way that can only occur when the two languages become part of the same dynamic language system (Perani \& Abutalebi, 2005).

Both the logic of the argument that uses evidence for a linear relation between age of acquisition and proficiency across the lifespan as justification for a $\mathrm{CP}$ and evidence from lifelong modifications in L1 that can be traced to the acquisition of an $\mathrm{L} 2$ in adulthood challenge the interpretation that critical periods constrain language acquisition. In this sense we agree with Mayberry and Kleunder but go further in questioning whether CP adds anything useful to the discussion about either L1 or L2 acquisition. There are, to be sure, age of acquisition effects on all these processes. But we see no evidence that these age-related effects reveal a critical period.

\section{References}

Ameel, E., Storms, G., Malt, B. C., \& Sloman, S. A. (2005). How bilinguals solve the naming problem. Journal of Memory and Language, 53, 60-80.

Baum, S., \& Titone, D. (2014). Moving toward a neuroplasticity view of bilingualism, executive control, and aging. Applied Psycholinguistics, 35, 857-894.

Beatty-Martínez, A. L., \& Dussias, P. E. (2017). Bilingual experience shapes language processing: Evidence from codeswitching. Journal of Memory and Language, 95, 173189.

Bialystok, E., \& Kroll, J.F. (in press). The neurobiology of language: Looking beyond monolinguals. Biolinguistics.

Bice, K., \& Kroll, J. F. (2015). Native language change during early stages of second language learning. NeuroReport, 26, 966-971.

DeKeyser, R., Alfi-Shabtay, I., \& Ravid, D. (2010). Crosslinguistic evidence for the nature of age effects in second language acquisition. Applied Psycholinguistics, 31, 413438. 
Dussias, P. E., \& Sagarra, N. (2007). The effect of exposure on syntactic parsing in Spanish-English bilinguals. Bilingualism: Language and Cognition, 10, 101-116.

Fricke, M., Zirnstein, M., Navarro-Torres, C., \& Kroll, J. F. (under review). Bilingualism reveals fundamental variation in language processing.

Goldberg, H., Paradis, J., \& Crago, M. (2008). Lexical acquisition over time in minority first language children learning English as a second language. Applied Psycholinguistics, 29, 41-65.

Hakuta, K., Bialystok, E., \& Wiley, E. (2003). Critical evidence: A test of the critical period hypothesis for second language acquisition. Psychological Science, 14, 31-38.

Johnson, J. S., \& Newport, E. L. (1989). Critical period effects in second language learning: The influence of maturational state on the acquisition of English as a second language. Cognitive Psychology, 21, 60-99.

Kasparian, K., \& Steinhauer, K. (2017). When the second language takes the lead: Neurocognitive processing changes in the first language of adult attriters. Frontiers in Psychology, 8.

Lewis, T. L., \& Maurer, D. (2005). Multiple sensitive periods in human visual development: evidence from visually deprived children. Developmental Psychobiology, 46, 163183.

Linck, J. A., Kroll, J. F., \& Sunderman, G. (2009). Losing access to the native language while immersed in a second language: Evidence for the role of inhibition in second language learning. Psychological Science, 20, 15071515 .
Mayberry, R. I., \& Kluender, R. (2017). Rethinking the critical period for language: New insights into an old question from American Sign Language. Bilingualism: Language and Cognition doi:10.1017/S1366728917000724

Morford, J. P., Wilkinson, E., Villwock, A., Piñar, P., \& Kroll, J. F. (2011). When deaf signers read English: Do written words activate their sign translations? Cognition, 118, 286292.

Pakulak, E., \& Neville, H. J. (2010). Proficiency differences in syntactic processing of monolingual native speakers indexed by event-related potentials. Journal of Cognitive Neuroscience, 22, 2728-2744.

Perani, D., \& Abutalebi, J. (2005). The neural basis of first and second language processing. Current Opinion in Neurobiology, 15, 202-206.

Pierce, L. J., Genesee, F., Delcenserie, A., \& Morgan, G. (2017). Variations in phonological working memory: Linking early language experiences and language learning outcomes. Applied Psycholinguistics, 38, 1265-1300.

Pyers, J. E., \& Emmorey, K. (2008). The face of bimodal bilingualism: Grammatical markers in American Sign Language are produced when bilinguals speak to English monolinguals. Psychological Science, 19, 531-535.

Snow, C. E. (1987). Relevance of the notion of a critical period to language acquisition. In M. Bornstein (Ed.), Sensitive periods in development: Interdisciplinary perspectives (pp. 183 209). Hillsdale, NJ: Erlbaum.

Tanner, D., \& Van Hell, J. G. (2014). ERPs reveal individual differences in morphosyntactic processing. Neuropsychologia, 56, 289-301. 